\title{
SÉRIES TEMPORAIS E APLICAÇÃO DOS ÍNDICES DE VEGETAÇÃO PARA CARACTERIZAÇÃO DA COBERTURA VEGETAL NO NÚCLEO DE DESERTIFICAÇÃO DE GILBUÉS, PI
}

\author{
AUTOR: TALIA SILVA RIBEIRO \\ CO-AUTOR/ORIENTADOR: GERSON DOS SANTOS LISBOA
}

Resumo: A desertificação é um processo de degradação que constitui graves problemas ambientais. Podendo ser ocasionados por fatores climáticos e atividades antrópicas. O presente trabalho objetivou analisar a cobertura vegetativa do núcleo de desertificação de Gilbués- PI. Assim, foram realizadas análises espectrais de imagens do satélite Landsat-5 TM e Landsat-8 OLI. O sistema de informação geográfica ARCGIS PRO e SPRING 5.5 foram utilizados para o pré-processamento e processamento das imagens. Para análise dos mapas foram realizados os cálculos de índices de vegetação (NDVI). Os mapas de uso e ocupação do solo da região apresentaram aumento nas atividades agrícolas de 134,4\% (1990 a 2000), $110,3 \%$ ( 2000 a 2010) e 105,9\% (2010 a 2018). Para aumento das áreas de solo exposto foi notório um aumento contínuo de 2000 até 2010. Ao analisar as classes de risco aos processos erosivos, cerca de 59\% da área encontrou-se sobre classes de solo de baixo risco. O NDVI mostrou-se eficiente para analisar o comportamento das áreas degradadas através das respostas de reflectância. Conclui-se que as maiores transformações foram o aumento da atividade agrícola e solo exposto. Os impactos ambientais resultantes sinalizam a necessidade de adoção de estratégias de conservação do solo para atenuar o avanço da desertificação e a manutenção das formações vegetais resilientes.

Palavras-chave: Desertificação, sensoriamento remoto, índice de vegetação. 